\title{
The clinicopathologic relevance and prognostic value of tumor deposits and the applicability of $N 1 c$ category in rectal cancer with preoperative radiotherapy
}

\author{
Xiao-li Wei ${ }^{1, *}$, Miao-zhen Qiu ${ }^{1,2, *}$, Yi-xin Zhou ${ }^{1, *}$, Ming-ming $\mathrm{He}^{1}$, Hui-yan Luo ${ }^{1}$, \\ Feng-hua Wang ${ }^{1}$, Dong-sheng Zhang ${ }^{1}$, Yu-hong $\mathbf{L i}^{1}$, Rui-hua $\mathbf{X u}^{1}$ \\ ${ }^{1}$ Department of Medical Oncology, Sun Yat-sen University Cancer Center, State Key Laboratory of Oncology in South China, \\ Collaborative Innovation Center for Cancer Medicine, Guangzhou 510060, China \\ ${ }^{2}$ Department of Pathology, The Johns Hopkins University School of Medicine, Baltimore, MD 21231, USA \\ *These authors have contributed equally to this work \\ Correspondence to: Rui-Hua XU, email: xurh@sysucc.org.cn \\ Keywords: rectal cancer, tumor deposits, preoperative radiotherapy, prognosis, SEER \\ Received: March 02, $2016 \quad$ Accepted: August 24, $2016 \quad$ Published: September 16, 2016
}

\section{ABSTRACT}

The clinicopathologic relevance and prognostic value of tumor deposits in colorectal cancer has been widely demonstrated. However, there are still debates in the prognostic value of tumor deposits and the applicability of N1c category in rectal cancer with preoperative radiotherapy. In this study, rectal cancer with preoperative radiotherapy followed by resection of primary tumors registered in Surveillance, Epidemiology and End Results (SEER) database from 2010-2012 were analyzed. There were 4,813 cases eligible for this study, and tumor deposits were found in $514(10.7 \%)$ cases. The presence of tumor deposits was significantly associated with some aggressive characteristics, including poorer tumor differentiation, more advanced ypT category, ypN category and ypTNM stage, distant metastasis, elevated carcinoembryonic antigen, higher positive rates of circumferential resection margin and perineural invasion (all $P<=0.001$ ). Tumor deposit was also an independent negative prognostic factor for cancer-specific survival in rectal cancer with preoperative radiotherapy (adjusted $H R$ and 95\% CI: $2.25(1.51-3.35)$ ). N1C category had significant worse survival compared with NO category (adjusted $H R$ and $95 \%$ CI: $2.41(1.24-4.69)$ ). In conclusion, tumor deposit was a significant and independent prognostic factor, and the N1C category by the $7^{\text {th }}$ edition of AJCC/TNM staging system was applicable in rectal cancer with preoperative radiotherapy.

\section{INTRODUCTION}

Rectal cancer is one of the most common malignancies of the digestive system. Along with colon cancer, it ranks near the top of cancer incidence and cause specific death worldwide [1-3]. Surgery is the only curable treatment for early stage cases [4]. Although some details remain to be explored, preoperative chemoradiotherapy has become the standard treatment strategy for locally advanced rectal cancer [5-10]. Adjuvant chemotherapy does not significantly reduce recurrence, improve diseasefree survival (DFS) or overall survival (OS) according to recent studies $[11,12]$. Identification of significant prognostic factors helps to determine subgroups with high risk, who may benefit from subsequent systemic chemotherapy.

The value of tumor deposits (TDs) has been widely explored in colorectal cancer. TDs have been reported to be associated with aggressive tumor features, including vascular invasion [13,14], perineural invasion [13], depth of tumor invasion and regional lymph nodes metastasis [15-17]. In addition, many studies have confirmed an inverse association of TDs with survival in colorectal cancer.

However, in rectal cancer with preoperative radiotherapy, only three studies investigated the prognostic value of TDs and debates existed. The first study specifically evaluating the prognostic value of TDs 
was conducted by Song JS et al. With a retrospective review of 136 rectal cancers staged at ypT3N0M0 after preoperative chemoradiotherapy, they identified TDs in 16 cases. They found no significant differences in both DFS and OS between TDs-negative and TDs-positive cases [18]. By contrast, Gopal P et al. analyzed 110 rectal cancers with preoperative chemoradiotherapy, and found TDs to be associated with a trend of higher local recurrence rate and significantly decreased survival [19]. Afterwards, another retrospective study by Zhang LN et al. with 310 locally advanced rectal cancer receiving preoperative chemoradiotherapy demonstrated TDs to be a significant negative prognostic factor for DFS and OS [20]. The conclusions were inconsistent and all the studies were of small sample sizes. Thus, we conducted this analysis with a large-sized sample based on Surveillance, Epidemiology and End Results (SEER) database to evaluate the prognostic value of TDs in rectal cancer with preoperative radiotherapy.

\section{RESULTS}

\section{The relevance of TDs with clinicopathologic characteristics in rectal cancer with preoperative radiotherapy}

In general, there were 14,572 rectal adenocarcinoma identified from SEER database in this study. After further selection of cases by the information of surgery and radiotherapy, we obtained 5,439 cases who received preoperative radiotherapy followed by resection of primary rectal cancer. Among them, the information for TDs (Absent / Present) was available in 4,813 (88.5\%) cases, and these cases were finally included in this study. TDs were present in $514(10.7 \%)$ cases. The presence of TDs was not associated with gender (Male / Female), age $(\leq 59 />59 \mathrm{yrs})$ nor tumor size $(\leq 4 />4 \mathrm{~cm})$. TDs was present in tumors with more aggressive features, including poorer differentiation, distant metastasis, higher carcinoembryonic antigen (CEA) level, higher rates of circumferential resection margin (CRM) involvement and perineural invasion (all $P<0.001$, Table 1 ). In addition, a sequential elevation of positive rate of TDs was presented along with the progression of ypT category, ypN category and ypTNM stage (all $P<0.001$, Table 1).

\section{The prognostic value of TDs in rectal cancer with preoperative radiotherapy}

We conducted univariate and multivariate analysis for the 4,813 rectal cancer cases in our study. By univariate analysis, tumor differentiation (Well differentiated / Moderately differentiated / Poorly differentiated or undifferentiated, $P<0.001$ ), ypT category (Tis $+\mathrm{T} 1 / \mathrm{T} 2$ / T3 / T4, $P<0.001$ ), ypN category (N0 / N1 / N2, $P<$ 0.001 ), distant metastasis (No / Yes, $P<0.001$ ), marital status (Widowed / Married / Others, $P=0.001$ ), CRM (Negative / Positive, $P<0.001$ ), perineural invasion (Negative / Positive, $P<0.001$ ) and TDs (Absent / Present, $P<0.001)$ were all found to be significant prognostic factors for rectal cancer-specific survival. All these factors were included for multivariate analysis. Only tumor differentiation $(P<0.001)$, N category $(P=0.05)$, marital status $(P=0.03)$, perineural invasion $(P=0.008)$ and TDs $(P<0.001$, hazard ratio $(H R)$ and $95 \%$ confidence interval $(C I): 2.25(1.51-3.35))$ were independent prognostic factors (Table 2). The survival curve of TDs (Absent / Present) plotted by the Kaplan-Meier method were shown in Figure 1.

\section{The prognostic value of TDs in regional lymph nodes negative rectal cancer with preoperative radiotherapy}

In the $7^{\text {th }}$ edition of AJCC/TNM staging system, TDs were adopted in regional lymph nodes negative colorectal cancer to establish a subclassification of N1c category. Since we had demonstrated the prognostic value of TDs in rectal cancer with preoperative radiotherapy, it was interesting to analyze the value of N1c category in rectal cancer with preoperative radiotherapy. There were 3,133 cases classified as regional lymph nodes negative among the 4,813 rectal cancer cases. We conducted univariate and multivariate survival analysis to evaluate the prognostic value of TDs in regional lymph nodes negative rectal cancer with preoperative radiotherapy. The results were shown in Table 3. Univariate analysis identified age $(\leq 60 />60$ yrs, $P=0.01)$, tumor differentiation (Well differentiated / Moderately differentiated / Poorly differentiated or undifferentiated, $P=0.04)$, ypT category (Tis+T1 / T2 / T3 / T4, $P<0.001$ ), distant metastasis (No / Yes, $P<0.001$ ), marital status (Widowed / Married / Others, $P=0.01$ ), CRM (Negative / Positive, $P=0.01$ ), perineural invasion (Negative / Positive, $P<0.001$ ) and TDs (Negative / Positive, $P<0.001$, Figure 2) to be significant prognostic factor for rectal cancer-specific survival. In multivariate analysis, TDs $(P=0.01, H R$ and 95\% CI: $2.41(1.24-4.69))$ remained as an independent prognostic factor. In addition, CRM $(P=0.02)$ and perineural invasion $(P=0.03)$ were also significant prognostic factors. Older patients $(>60 \mathrm{yrs})$ were found to have a trend of worse survival than younger $(P=0.06)$. Since regional lymph nodes negative cases with TDs was classified as N1c in the $7^{\text {th }}$ AJCC/TNM staging system, our analysis proved the rationale of N1c category in rectal cancer with preoperative radiotherapy.

\section{DISCUSSION}

We demonstrated the prognostic value of TDs and the rational of N1c category in rectal cancer with preoperative radiotherapy using the SEER database 
Table 1: The association of tumor deposits with clinicopathologic characteristics in rectal cancer with preoperative radiotherapy

\begin{tabular}{|c|c|c|c|}
\hline \multirow{2}{*}{ Characteristics } & \multicolumn{2}{|c|}{ Tumor deposits N (\%) } & \multirow{2}{*}{$P$ value } \\
\hline & Absent & Present & \\
\hline Gender & & & 0.65 \\
\hline Male & $2,696(89.5)$ & $317(10.5)$ & \\
\hline Female & $1,603(89.1)$ & $197(10.9)$ & \\
\hline Age (yrs, median: 59) & & & 0.39 \\
\hline$\leq 59$ & $2,146(88.9)$ & $267(11.1)$ & \\
\hline$>59$ & $2,153(89.7)$ & $247(10.3)$ & \\
\hline Grade & & & $<0.001^{\mathrm{a}}$ \\
\hline Well differentiated & $257(91.8)$ & $23(8.2)$ & \\
\hline Moderately differentiated & $3,096(89.7)$ & $355(10.3)$ & \\
\hline $\begin{array}{l}\text { Poorly differentiated or } \\
\text { undifferentiated }\end{array}$ & $489(83.2)$ & $99(16.8)$ & \\
\hline Primary tumor size $(\mathrm{cm})$ & & & 0.58 \\
\hline$\leq 4$ & $1,927(88.9)$ & $240(11.1)$ & \\
\hline$>4$ & $1,618(88.4)$ & $213(11.6)$ & \\
\hline урТ category & & & $<0.001^{\mathrm{a}}$ \\
\hline Tis & $19(100.0)$ & $0(0.0)$ & \\
\hline $\mathrm{T} 1$ & $232(97.9)$ & $5(2.1)$ & \\
\hline $\mathrm{T} 2$ & $586(95.1)$ & $30(4.9)$ & \\
\hline $\mathrm{T} 3$ & $3,099(88.5)$ & $404(11.5)$ & \\
\hline $\mathrm{T} 4$ & $362(82.8)$ & $75(17.2)$ & \\
\hline ypN category & & & $<0.001^{\mathrm{a}}$ \\
\hline No & $2,250(96.7)$ & $76(3.3)$ & \\
\hline N1 & $1,650(84.0)$ & $315(16.0)$ & \\
\hline $\mathrm{N} 2$ & $399(76.4)$ & $123(23.6)$ & \\
\hline Distant metastasis & & & $<0.001^{\mathrm{a}}$ \\
\hline No & $4,075(90.1)$ & $448(9.9)$ & \\
\hline Yes & $224(77.2)$ & $66(22.8)$ & \\
\hline ypTNM stage & & & $<0.001^{\mathrm{a}}$ \\
\hline 0 & $19(100.0)$ & $0(0.0)$ & \\
\hline I & $552(98.9)$ & $6(1.1)$ & \\
\hline II & $1,615(96.3)$ & $62(3.7)$ & \\
\hline III & $1,889(83.3)$ & $380(16.7)$ & \\
\hline IV & $224(77.2)$ & $66(22.8)$ & \\
\hline CEA & & & $<0.001^{\mathrm{a}}$ \\
\hline Normal & $1,635(91.5)$ & $152(8.5)$ & \\
\hline Borderline & $19(90.5)$ & $2(9.5)$ & \\
\hline Elevated & $1,252(85.3)$ & $215(14.7)$ & \\
\hline CRM & & & $<0.001^{\mathrm{a}}$ \\
\hline Negative & $1,955(89.8)$ & $221(10.2)$ & \\
\hline Positive & $503(77.9)$ & $143(22.1)$ & \\
\hline Perineural invasion & & & $<0.001^{\mathrm{a}}$ \\
\hline Negative & $3,533(91.9)$ & $313(8.1)$ & \\
\hline Positive & $310(66.1)$ & $159(33.9)$ & \\
\hline
\end{tabular}

a: Significant $P$ value.

Abbreviation: CEA, carcinoembryonic antigen, CRM, circumferential resection margin. 
Table 2: Univariate and multivariate analysis for the prognostic value of tumor deposits in rectal cancer with preoperative radiotherapy

\begin{tabular}{|c|c|c|c|c|c|c|c|}
\hline \multirow[b]{2}{*}{ Characteristics } & \multicolumn{4}{|c|}{ Univariate analysis } & \multicolumn{3}{|c|}{ Multivariate analysis } \\
\hline & No. $(\%)$ & $H R$ & $95 \% C I$ & $P$ value & $\begin{array}{c}\text { Adjusted } \\
\text { HR }\end{array}$ & $95 \% C I$ & $P$ value \\
\hline Sex & & 0.87 & $0.67-1.13$ & 0.29 & & & \\
\hline Male & $3013(62.6)$ & & & & & & \\
\hline Female & $1800(37.4)$ & & & & & & \\
\hline Age (yrs, median: 59) & & 1.24 & $0.97-1.59$ & 0.08 & & & \\
\hline$\leq 59$ & $2,413(50.1)$ & & & & & & \\
\hline$>59$ & $2,400(49.9)$ & & & & & & \\
\hline Grade & & & & $<0.001^{\mathrm{a}}$ & & & $<0.001^{\mathrm{a}}$ \\
\hline Well differentiated & $280(6.5)$ & 1 & Reference & & 1 & Reference & \\
\hline $\begin{array}{l}\text { Moderately } \\
\text { differentiated }\end{array}$ & 3451 (79.9) & 0.81 & $0.47-1.40$ & 0.44 & 1.07 & $0.43-2.65$ & 0.89 \\
\hline $\begin{array}{l}\text { Poorly differentiated } \\
\text { or undifferentiated }\end{array}$ & $588(13.6)$ & 2.93 & $1.67-5.16$ & $<0.001^{\mathrm{ab}}$ & 3.40 & $1.34-8.60$ & $0.01^{\mathrm{a}}$ \\
\hline ypT category & & & & $<0.001^{\mathrm{a}}$ & & & 0.12 \\
\hline Tis $+\mathrm{T} 1$ & $256(5.3)$ & 1 & Reference & & 1 & Reference & \\
\hline $\mathrm{T} 2$ & $616(12.8)$ & 1.45 & $0.58-3.60$ & 0.43 & 1.26 & $0.28-5.69$ & 0.77 \\
\hline $\mathrm{T} 3$ & $3503(72.8)$ & 2.39 & $1.06-5.39$ & 0.04 & 1.31 & $0.32-5.39$ & 0.71 \\
\hline $\mathrm{T} 4$ & $437(9.1)$ & 5.90 & $2.54-13.74$ & $<0.001^{\mathrm{ab}}$ & 2.20 & $0.51-9.46$ & 0.29 \\
\hline ypN category & & & & $<0.001^{\mathrm{a}}$ & & & $0.05^{\mathrm{a}}$ \\
\hline No & $2326(48.2)$ & 1 & Reference & & 1 & Reference & \\
\hline N1 & $1965(40.8)$ & 1.63 & $1.23-2.16$ & $0.01^{\mathrm{ab}}$ & 0.95 & $0.62-1.47$ & 0.82 \\
\hline $\mathrm{N} 2$ & $522(10.8)$ & 3.55 & $2.55-4.93$ & $<0.001^{\mathrm{ab}}$ & 1.59 & $0.98-2.58$ & 0.06 \\
\hline Distant metastasis & & 4.47 & $3.33-6.01$ & $<0.001^{\mathrm{a}}$ & 3.34 & $2.17-5.13$ & $<0.001^{\mathrm{a}}$ \\
\hline No & $4523(94.0)$ & & & & & & \\
\hline Yes & $290(6.0)$ & & & & & & \\
\hline Marital status & & & & $0.001^{\mathrm{a}}$ & & & $0.03^{\mathrm{a}}$ \\
\hline Widowed & $354(7.4)$ & 1 & Reference & & 1 & Reference & \\
\hline Married & $2,896(60.2)$ & 0.53 & $0.36-0.80$ & $0.002^{\mathrm{ab}}$ & 0.57 & $0.30-1.06$ & 0.07 \\
\hline Others & $1,563(32.4)$ & 0.79 & $0.53-1.20$ & 0.27 & 0.88 & $0.47-1.66$ & 0.70 \\
\hline CRM & & 2.05 & $1.47-2.85$ & $<0.001^{\mathrm{a}}$ & 1.38 & $0.97-1.98$ & 0.09 \\
\hline Negative & $2,176(77.1)$ & & & & & & \\
\hline Positive & $646(22.9)$ & & & & & & \\
\hline Perineural Invasion & & 3.15 & $2.34-4.24$ & $<0.001^{\mathrm{a}}$ & 1.76 & $1.16-2.66$ & $0.008^{\mathrm{a}}$ \\
\hline Negative & $3,846(89.1)$ & & & & & & \\
\hline Positive & $469(10.9)$ & & & & & & \\
\hline Tumor deposits & & 3.05 & $2.31-4.03$ & $<0.001^{\mathrm{a}}$ & 2.25 & $1.51-3.35$ & $<0.001^{\mathrm{a}}$ \\
\hline Absent & 4,299 (89.3) & & & & & & \\
\hline Present & $514(10.7)$ & & & & & & \\
\hline
\end{tabular}

a Significant $P$ value.

b Significant $P$ value after Bonferroni correction.

Abbreviation: CRM, circumferential resection margin. $H R$, hazard ratio, $C I$, confidence interval. 
registered from $2010-2012$ in this study. To our knowledge, this was so far the largest study to investigate the prognostic value of TDs in rectal cancer with preoperative radiotherapy.

Firstly mentioned in the $5^{\text {th }}$ edition of AJCC/ TNM staging system, the definition of TDs had evolved along with the release of subsequent editions. During the evolution of TDs definition, the clinicopathologic relevance and prognostic value of TDs had been widely investigated and confirmed in colorectal cancer [13, 15, 17, 21-24]. However, the applicability of TDs in rectal cancer with preoperative chemoradiotherapy had been doubted due to pathological changes induced by chemoradiotherapy. The feature of tumor regression might present with tumor nodules surrounded by fibroinflammatory stroma, which might cause confusion to distinguish residual microfoci and TDs [25, 26]. Thus the value of TDs in rectal cancer with preoperative chemoradiotherapy needed further assessment.

In rectal cancer receiving preoperative radiotherapy, consistent with the findings by Gopal P et al [19] and Zhang LN et al [20], we demonstrated the relevance of TDs with several aggressive tumor features, including more intensive regional lymph nodes metastasis [19, 20], more perineural invasion [19] and higher CEA level [20]. In addition, we also found TDs to be significantly associated with poorer tumor differentiation, more advanced ypT category and ypTNM stage, distant metastasis, as well as higher positive rates of CRM involvement and perineural invasion. It seemed that TDs was not only indicators of more advanced tumor stage, but also associated with intrinsic tumor aggressiveness. Our study also verified the prognostic value of TDs for rectal cancer-specific survival in rectal cancer with preoperative radiotherapy, which was in accordance with the studies by Gopal P et al and Zhang LN et al. Furthermore, by demonstrating the significant and independent prognostic value of TDs in regional lymph nodes negative group, we also proved the applicability of N1c category established by the $7^{\text {th }}$ edition of AJCC/TNM staging system in rectal cancer with preoperative radiotherapy.

Interestingly, in our study, by univariate analysis, although ypT and ypN categories were significant prognostic factors for rectal cancer-specific survival, after adjusting by other prognostic factors, ypT category turned out to be not an independent prognostic factor in rectal cancer with preoperative radiotherapy, and also in cases with negative regional lymph nodes. We further conducted univariate and multivariate analysis for the prognostic value of ypTNM stage $(0+\mathrm{I} / \mathrm{II} / \mathrm{III} /$ IV) in rectal cancer with preoperative radiotherapy (Supplementary Table S1). We found that only stage IV

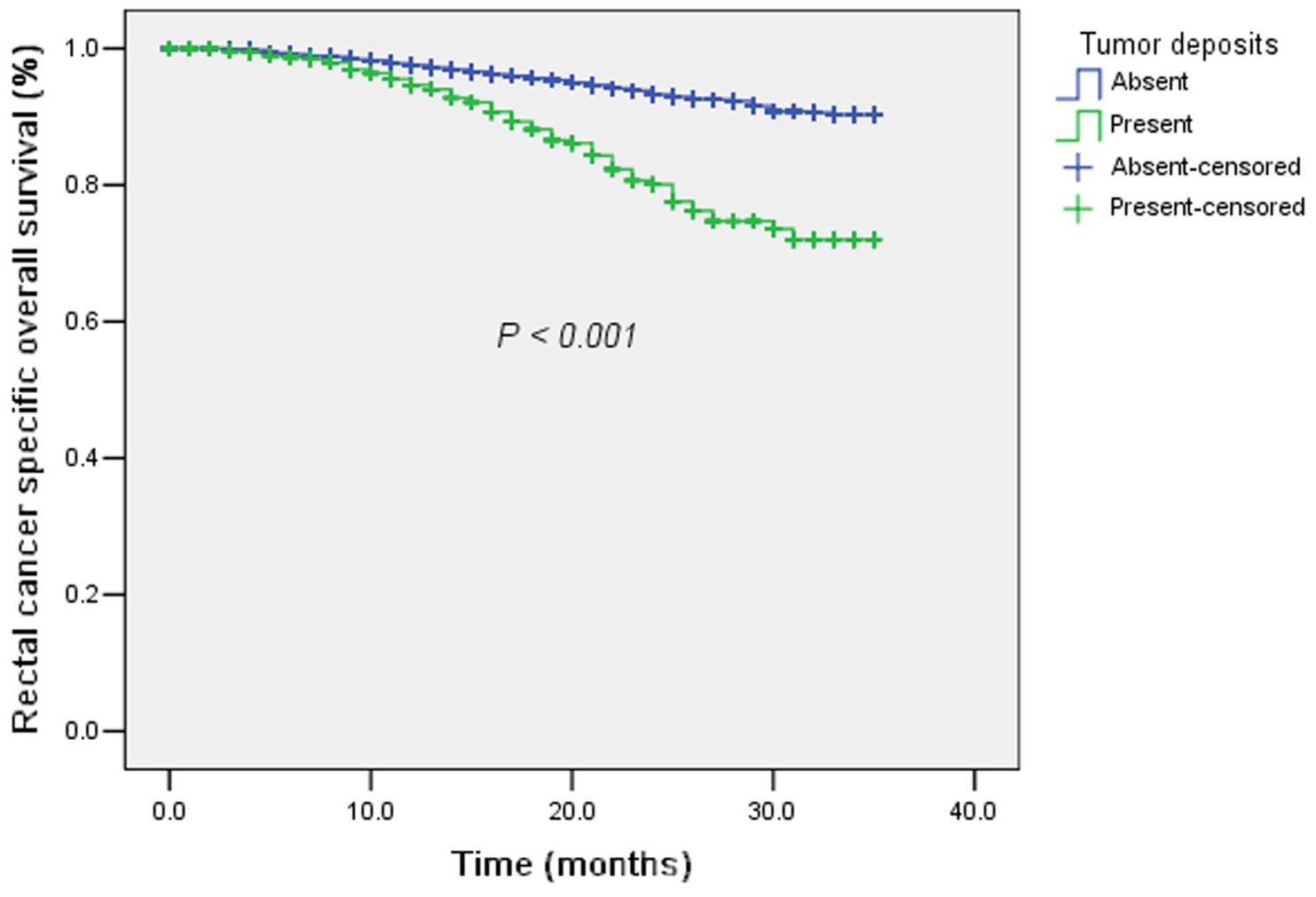

Figure 1: The survival curves of tumor deposits (Absent / Present) plotted by the Kaplan-Meier method in rectal cancer with preoperative radiotherapy. Patients with tumor deposits had significantly worse rectal cancer-specific survival compared with those without tumor deposits. 
Table 3: Univariate and multivariate analysis for the prognostic value of tumor deposits in regional lymph nodes negative rectal cancer with preoperative radiotherapy

\begin{tabular}{|c|c|c|c|c|c|c|c|}
\hline \multirow[b]{2}{*}{ Characteristics } & \multicolumn{4}{|c|}{ Univariate analysis } & \multicolumn{3}{|c|}{ Multivariate analysis } \\
\hline & No. $(\%)$ & $H R$ & $95 \% C I$ & $P$ value & $\begin{array}{l}\text { Adjusted } \\
\qquad H R\end{array}$ & $95 \% C I$ & $P$ value \\
\hline Sex & & 0.92 & $0.59-1.43$ & 0.89 & & & \\
\hline Male & $1,962(62.6)$ & & & & & & \\
\hline Female & $1,171(37.4)$ & & & & & & \\
\hline Age (yrs, median: 60) & & 1.69 & $1.09-2.62$ & $0.01^{\mathrm{a}}$ & 1.70 & $0.98-2.98$ & 0.06 \\
\hline$\leq 60$ & $1,615(51.5)$ & & & & & & \\
\hline$>60$ & $1,518(48.5)$ & & & & & & \\
\hline Grade & & & & $0.04^{\mathrm{a}}$ & & & 0.15 \\
\hline Well differentiated & $198(7.1)$ & 1 & Reference & & 1 & Reference & \\
\hline $\begin{array}{l}\text { Moderately } \\
\text { differentiated }\end{array}$ & $2,303(82.7)$ & 0.73 & $0.33-1.60$ & 0.43 & 0.77 & $0.23-2.52$ & 0.66 \\
\hline $\begin{array}{l}\text { Poorly differentiated } \\
\text { or undifferentiated }\end{array}$ & $285(10.2)$ & 1.45 & $0.59-3.60$ & 0.42 & 1.51 & $0.41-5.61$ & 0.54 \\
\hline ypT category & & & & $<0.001^{\mathrm{a}}$ & & & 0.21 \\
\hline Tis $+\mathrm{T} 1$ & $183(5.8)$ & 1 & Reference & & 1 & Reference & \\
\hline $\mathrm{T} 2$ & $433(13.8)$ & 1.36 & $0.43-4.33$ & 0.61 & 1.77 & $0.21-14.73$ & 0.60 \\
\hline $\mathrm{T} 3$ & $2,271(72.5)$ & 1.82 & $0.66-5.02$ & 0.25 & 1.46 & $0.20-10.76$ & 0.71 \\
\hline $\mathrm{T} 4$ & $246(7.9)$ & 6.13 & $2.08-18.01$ & $0.001^{\mathrm{ab}}$ & 3.04 & $0.38-24.21$ & 0.29 \\
\hline Distant metastasis & & 4.41 & $2.34-8.31$ & $<0.001^{\mathrm{a}}$ & 2.54 & $1.00-6.47$ & 0.05 \\
\hline No & $3,013(96.2)$ & & & & & & \\
\hline Yes & $120(3.8)$ & & & & & & \\
\hline Marital status & & & & $0.01^{\mathrm{a}}$ & & & 0.60 \\
\hline Widowed & $240(7.7)$ & 1 & Reference & & 1 & Reference & \\
\hline Married & $1,871(59.7)$ & 0.47 & $0.25-0.88$ & $0.01^{\mathrm{ab}}$ & 1.12 & $0.38-3.31$ & 0.83 \\
\hline Others & $1,022(32.6)$ & 0.63 & $0.33-1.20$ & 0.16 & 1.47 & $0.49-4.42$ & 0.50 \\
\hline CRM & & 1.95 & $1.07-3.56$ & $0.01^{\mathrm{a}}$ & 2.00 & $1.12-3.56$ & $0.02^{\mathrm{a}}$ \\
\hline Negative & $1,434(80.1)$ & & & & & & \\
\hline Positive & 357 (19.9) & & & & & & \\
\hline Perineural Invasion & & 2.82 & $1.48-5.35$ & $<0.001^{\mathrm{a}}$ & 2.21 & $1.10-4.47$ & $0.03^{\mathrm{a}}$ \\
\hline Negative & $2,626(93.1)$ & & & & & & \\
\hline Positive & $194(6.9)$ & & & & & & \\
\hline Tumor deposits & & 3.34 & $1.77-6.29$ & $<0.001^{\mathrm{a}}$ & 2.41 & $1.24-4.69$ & $0.01^{\mathrm{a}}$ \\
\hline Absent & $2,916(93.1)$ & & & & & & \\
\hline Present & 217 (6.9) & & & & & & \\
\hline
\end{tabular}

a: Significant $P$ value.

b Significant $P$ value after Bonferroni correction.

Abbreviation: CRM, circumferential resection margin. $H R$, hazard ratio, $C I$, confidence interval. 
patients had significant different survival compared with stage $0+\mathrm{I}$ patients. This discovery called for a survey of literatures about the applicability of ypTNM stage in rectal cancer with preoperative radiotherapy or preoperative chemoradiotherapy. As a result, we found that it was actually not profoundly researched. Song JS et al proposed the irrelevance of ypTNM stage with DFS and OS in rectal cancer with preoperative chemoradiotherapy [18]. Although several other studies indicated strong association of ypTNM stage and survival in rectal cancer with preoperative chemoradiotherapy, their conclusions were based on univariate analysis $[20,27]$ or incomplete multivariate analysis [28, 29], for example, adjusted only by age and sex [28]. We didn't find any study to include some important postoperative pathological factors in survival analysis, such as TDs and CRM. Since our study identified these postoperative pathological features to have even more important prognostic value compared with ypT category and ypTNM stage, more comprehensive investigations about the applicability of ypTNM stage in rectal cancer with preoperative radiotherapy were further needed, especially for those without distant metastasis.

Several limitations of our study were noteworthy. Because information of chemotherapy was not available in the SEER database, we could only include rectal cancer with preoperative radiotherapy for analysis in this study. Chemoradiotherapy was the standard treatment for rectal cancer, thus this was one of the major limitations in our study. In addition, several important pathologic factors, including tumor regression grade and vascular invasion were not accessible, thus the conclusions of our study were not adjusted by these important prognostic factors. More importantly, the inter-observer variability in diagnosing TDs was particularly challenging for SEER data due to the various pathologists involved in the data generation. In addition, radiotherapy could increase tissue fibrosis and might cause false-positive diagnoses of TDs. The uniformity of diagnosis and possible false-positive diagnosis were major limitations in our study. These limitations couldn't be resolved and should be particularly noticed in our study with SEER data. Given these limitations, a further verification of our conclusions using a population with more complete information was warranted. In conclusion, tumor deposit was a significant and independent prognostic factor, and N1c category by the $7^{\text {th }}$ edition of AJCC/TNM staging system was applicable in rectal cancer with preoperative radiotherapy.

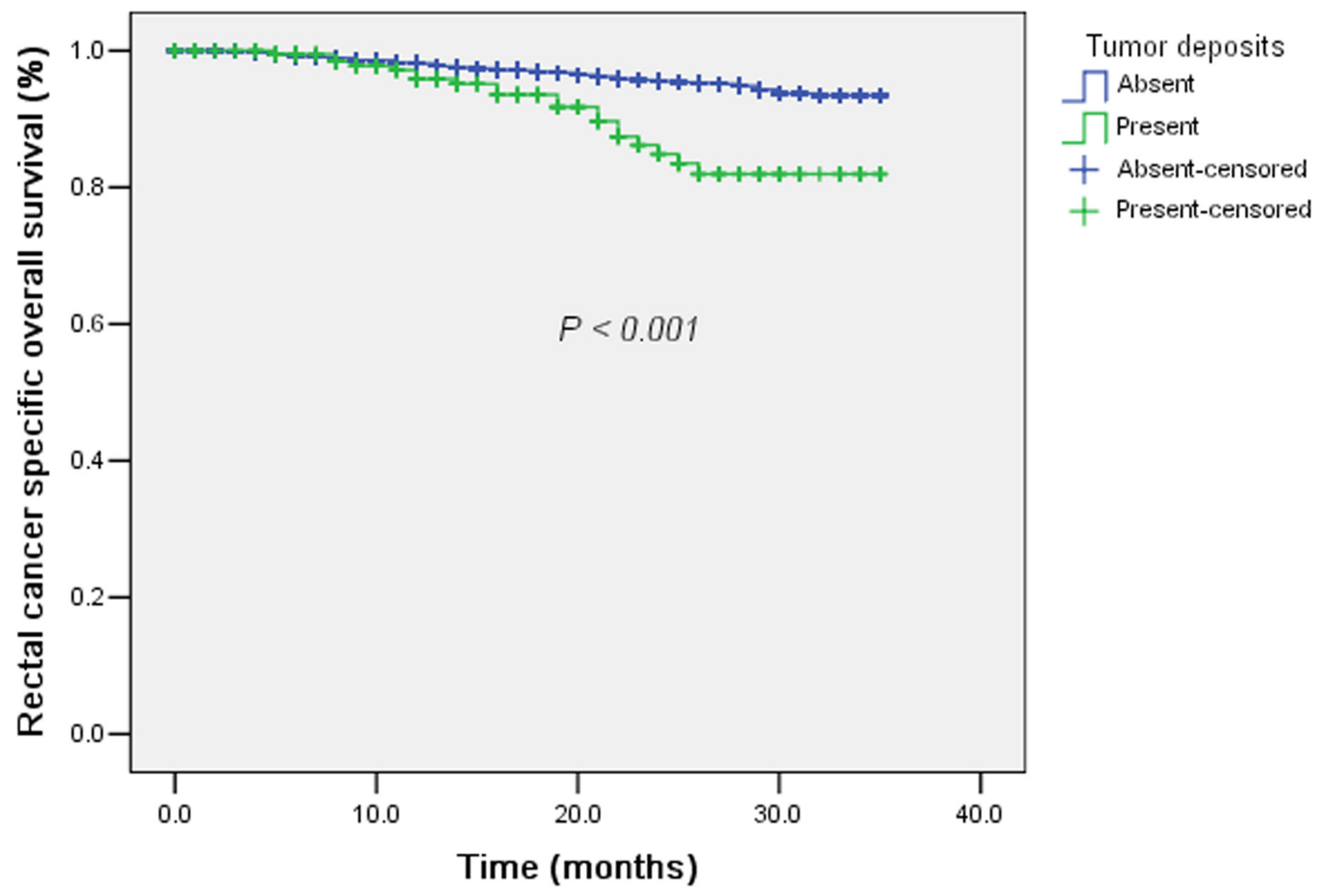

Figure 2: The survival curves of tumor deposits (Absent / Present) plotted by the Kaplan-Meier method in regional lymph nodes negative rectal cancer with preoperative radiotherapy. Patients with tumor deposits (categorized as N1c category) had significantly worse rectal cancer-specific survival compared with those without tumor deposits (N0 category). 


\section{MATERIALS AND METHODS}

\section{Ethics statement}

This study was deemed exempt from institutional review board approval by Sun Yat-sen University Cancer Center and informed consent was waived. This study was conducted in accordance with the ethical standards of the World Medical Association Declaration of Helsinki.

\section{SEER database and case selection}

The dataset used for analysis in this study was based on the November 2014 data submission "Incidence-SEER 18 Regs Research Data + Hurricane Katrina Impacted Louisiana Cases, Nov 2014 Sub (1973-2012 varying)". According to the International Classification of Diseases for Oncology, third edition (ICD-O-3) topography codes and histology codes, adenocarcinoma (Code $8140-$ $8147,8210-8211,8220-8221,8255,8260-8263$, $8480-8481,8490$ and 8574 ) of rectum (Code C20.9) was included in this study. In addition, we restricted eligibility to patients with records of the $7^{\text {th }}$ American Joint Committee on Cancer/tumor node metastasis (AJCC/ TNM) category from 2010 to 2012. We also excluded cases without follow-up records (survival time code of 0 months) and patients with primary tumors other than rectal cancer. Further limitations about radiation (Radiation sequence with surgery) and surgery (RX Summ--Surg Prim Site (1998+)) were also considered for the final study population.

\section{Information for tumor deposits}

Tumor deposits were defined as follows in the $7^{\text {th }}$ edition of AJCC/TNM staging system: "The deposit should be in the pericolorectal fat or adjacent mesocolic fat, it should be away from the leading edge of the tumor, there should be no evidence of residual lymph node tissue, and finally the tumor deposit should be within the lymph drainage area of the primary carcinoma". This was different from previous definitions which laid more importance on the size and shape of tumor nodules in the $5^{\text {th }}$ and $6^{\text {th }}$ edition of AJCC/TNM staging system. With the implement of Collaborative Stage Data Collection System Version 2 (CSv2) in 2010, the information of TDs was recorded in SEER database as site-specific factor (SSF) 4. The codes and description of the SSFs are available at https://cancerstaging.org/cstage/schema/Pages/ version0205.aspx.

\section{Statistical analysis}

We performed all the analyses with SPSS for windows V.13.0. (SPSS Inc., Chicago, IL, USA). The association of TDs with clinicopathologic features was conducted using chi-square test or Kruskal-Wallis $\mathrm{H}$ test. Rectal cancer-specific survival was calculated as the time interval between the diagnosis of rectal cancer and the death attributed to rectal cancer, or censored at the death from other causes or the last visit. Univariate and multivariate survival analyses were computed for the prognostic value of TDs for rectal cancer-specific survival. Survival curves were plotted by the Kaplan-Meier method and compared using the log-rank test. $H R$ and $95 \% C I$ were computed with the cox proportional hazards model. A two tailed $P$ value $<0.05$ was considered statistically significant. Bonferroni correction was applied in univariate analysis.

\section{ACKNOWLEDGMENTS}

The authors gratefully acknowledge the staff members of the National Cancer Institute and their colleagues across the United States and at Information Management Services, Inc., who have been involved with the SEER Program. In addition, they acknowledge Professor Ying Guo for her assistance in statistical analysis.

\section{CONFLICTS OF INTEREST}

The authors declare no conflicts of interest in this study.

\section{GRANT SUPPORT}

This work was supported by:

1. The Fundamental Research Funds for the Central Universities, 16ykpy25.

2. China Scholarship Council, 201406385034.

3 . The third outstanding young talents training plan of Sun Yat-sen University cancer center.

4. Medical Scientific Research of Guangdong province B2014161.

5. Science and Technology Planning Project of Guangdong Province (No. 2013A022100023).

6. National High Technology Research and Development Program of China (863 Program), China (No. 2015AA020103).

7. National Natural Science Foundation of China No.81372570, 81572392)

8. Natural Science Foundation of Guangdong Province (No.2014A030312015)

9. Science and Technology Program of Guangzhou (No. 15570006, 158100066).

\section{REFERENCES}

1. Chen W, Zheng R, Baade PD, Zhang S, Zeng H, Bray F, Jemal A, Yu XQ, He J. Cancer statistics in China, 2015. CA Cancer J Clin. 2016. 
2. Siegel RL, Miller KD, Jemal A. Cancer statistics, 2016. CA Cancer J Clin. 2016; 66:7-30.

3. Chen W, Zheng R, Zeng H, Zhang S. The updated incidences and mortalities of major cancers in China, 2011. Chin J Cancer. 2015; 34:53.

4. Heald RJ, Ryall RD. Recurrence and survival after total mesorectal excision for rectal cancer. Lancet. 1986; 1:1479-1482.

5. Gerard JP, Conroy T, Bonnetain F, Bouche O, Chapet O, Closon-Dejardin MT, Untereiner M, Leduc B, Francois E, Maurel J, Seitz JF, Buecher B, Mackiewicz R, Ducreux $\mathrm{M}$, Bedenne L. Preoperative radiotherapy with or without concurrent fluorouracil and leucovorin in T3-4 rectal cancers: results of FFCD 9203. J Clin Oncol. 2006; 24:4620-4625.

6. Rodel C, Graeven U, Fietkau R, Hohenberger W, Hothorn T, Arnold D, Hofheinz RD, Ghadimi M, Wolff HA, LangWelzenbach M, Raab HR, Wittekind C, Strobel P, et al. Oxaliplatin added to fluorouracil-based preoperative chemoradiotherapy and postoperative chemotherapy of locally advanced rectal cancer (the German CAO/ARO/ AIO-04 study): final results of the multicentre, open-label, randomised, phase 3 trial. Lancet Oncol. 2015; 16:979-989.

7. Hong YS, Nam BH, Kim KP, Kim JE, Park SJ, Park YS, Park JO, Kim SY, Kim TY, Kim JH, Ahn JB, Lim SB, Yu $\mathrm{CS}$, et al. Oxaliplatin, fluorouracil, and leucovorin versus fluorouracil and leucovorin as adjuvant chemotherapy for locally advanced rectal cancer after preoperative chemoradiotherapy (ADORE): an open-label, multicentre, phase 2, randomised controlled trial. Lancet Oncol. 2014; 15:1245-1253.

8. Rodel C, Liersch T, Becker H, Fietkau R, Hohenberger W, Hothorn T, Graeven U, Arnold D, Lang-Welzenbach M, Raab HR, Sulberg H, Wittekind C, Potapov S, et al. Preoperative chemoradiotherapy and postoperative chemotherapy with fluorouracil and oxaliplatin versus fluorouracil alone in locally advanced rectal cancer: initial results of the German $\mathrm{CAO} / \mathrm{ARO} / \mathrm{AIO}-04$ randomised phase 3 trial. Lancet Oncol. 2012; 13:679-687.

9. van Gijn W, Marijnen CA, Nagtegaal ID, Kranenbarg EM, Putter H, Wiggers T, Rutten HJ, Pahlman L, Glimelius B, van de Velde CJ. Preoperative radiotherapy combined with total mesorectal excision for resectable rectal cancer: 12-year follow-up of the multicentre, randomised controlled TME trial. Lancet Oncol. 2011; 12:575-582.

10. Fan WH, Wang FL, Lu ZH, Pan ZZ, Li LR, Gao YH, Chen G, Wu XJ, Ding PR, Zeng ZF, Wan DS. Surgery with versus without preoperative concurrent chemoradiotherapy for mid/low rectal cancer: an interim analysis of a prospective, randomized trial. Chin J Cancer. 2015; 37:25.

11. Breugom AJ, Swets M, Bosset JF, Collette L, Sainato A, Cionini L, Glynne-Jones R, Counsell N, Bastiaannet E, van den Broek CB, Liefers GJ, Putter H, van de Velde CJ. Adjuvant chemotherapy after preoperative (chemo) radiotherapy and surgery for patients with rectal cancer: a systematic review and meta-analysis of individual patient data. Lancet Oncol. 2015; 16:200-207.
12. Park IJ, Kim DY, Kim HC, Kim NK, Kim HR, Kang SB, Choi GS, Lee KY, Kim SH, Oh ST, Lim SB, Kim JC, Oh $\mathrm{JH}$, et al. Role of Adjuvant Chemotherapy in ypT0-2N0 Patients Treated with Preoperative Chemoradiation Therapy and Radical Resection for Rectal Cancer. Int J Radiat Oncol Biol Phys. 2015; 92:540-547.

13. Prabhudesai A, Arif S, Finlayson CJ, Kumar D. Impact of microscopic extranodal tumor deposits on the outcome of patients with rectal cancer. Dis Colon Rectum. 2003; 46:1531-1537.

14. Tateishi S, Arima S, Futami K, Kawahara K, Tachikawa D, Naritomi K, Iwashita A. A clinicopathological investigation of "tumor nodules" in colorectal cancer. Surg Today. 2005; 35:377-384.

15. Yamano T, Semba S, Noda M, Yoshimura M, Kobayashi M, Hamanaka M, Beppu N, Yano A, Tsukamoto K, Matsubara N, Tomita N. Prognostic significance of classified extramural tumor deposits and extracapsular lymph node invasion in T3-4 colorectal cancer: a retrospective singlecenter study. Bmc Cancer. 2015; 15:859.

16. Nagayoshi K, Ueki T, Nishioka Y, Manabe T, Mizuuchi Y, Hirahashi M, Oda Y, Tanaka M. Tumor deposit is a poor prognostic indicator for patients who have stage II and III colorectal cancer with fewer than 4 lymph node metastases but not for those with 4 or more. Dis Colon Rectum. 2014; 57:467-474.

17. Tong LL, Gao P, Wang ZN, Song YX, Xu YY, Sun Z, Xing $\mathrm{CZ}, \mathrm{Xu}$ HM. Is the seventh edition of the UICC/AJCC TNM staging system reasonable for patients with tumor deposits in colorectal cancer? Ann Surg. 2012; 255:208-213.

18. Song JS, Chang HJ, Kim DY, Kim SY, Baek JY, Park JW, Park SC, Choi HS, Oh JH. Is the N1c category of the new American Joint Committee on cancer staging system applicable to patients with rectal cancer who receive preoperative chemoradiotherapy? Cancer. 2011; 117:3917-3924.

19. Gopal P, Lu P, Ayers GD, Herline AJ, Washington MK. Tumor deposits in rectal adenocarcinoma after neoadjuvant chemoradiation are associated with poor prognosis. Mod Pathol. 2014; 27:1281-1287.

20. Zhang LN, Xiao WW, Xi SY, OuYang PY, You KY, Zeng ZF, Ding PR, Zhang HZ, Pan ZZ, Xu RH, Gao YH. Tumor deposits: markers of poor prognosis in patients with locally advanced rectal cancer following neoadjuvant chemoradiotherapy. Oncotarget. 2016; 7:6335-6344. doi: 10.18632/oncotarget.6656.

21. Goldstein NS, Turner JR. Pericolonic tumor deposits in patients with $\mathrm{T} 3 \mathrm{~N}+\mathrm{MO}$ colon adenocarcinomas: markers of reduced disease free survival and intra-abdominal metastases and their implications for TNM classification. Cancer. 2000; 88:2228-2238.

22. Belt EJ, van Stijn MF, Bril H, de Lange-de KE, Meijer GA, Meijer S, Stockmann HB. Lymph node negative colorectal cancers with isolated tumor deposits should be classified and treated as stage III. Ann Surg Oncol. 2010; 17:3203-3211. 
23. Jin M, Roth R, Rock JB, Washington MK, Lehman A, Frankel WL. The impact of tumor deposits on colonic adenocarcinoma AJCC TNM staging and outcome. Am J Surg Pathol. 2015; 39:109-115.

24. Mayo E, Llanos AA, Yi X, Duan SZ, Zhang L. Prognostic Value of Tumor Deposit and Perineural Invasion Status in Colorectal Cancer Patients: a SEER-Based Population Study. Histopathology. 2016.

25. Dworak O, Keilholz L, Hoffmann A. Pathological features of rectal cancer after preoperative radiochemotherapy. Int J Colorectal Dis. 1997; 12:19-23.

26. Allen DC, Fon LJ, McAleer JJ, Irwin ST. Pathology of rectal adenocarcinoma following preoperative adjuvant radiotherapy and chemotherapy. Ulster Med J. 1999; 68:17-21.

27. Kuo LJ, Liu MC, Jian JJ, Horng CF, Cheng TI, Chen CM, Fang WT, Chung YL. Is final TNM staging a predictor for survival in locally advanced rectal cancer after preoperative chemoradiation therapy? Ann Surg Oncol. 2007; 14:2766-2772.

28. Wen B, Zhang L, Wang C, Huang R, Peng H, Zhang T, Dong J, Xiao W, Zeng Z, Liu M, Gao Y. Prognostic significance of clinical and pathological stages on locally advanced rectal carcinoma after neoadjuvant chemoradiotherapy. Radiat Oncol. 2015; 10:124.

29. Chan AK, Wong A, Jenken D, Heine J, Buie D, Johnson D. Posttreatment TNM staging is a prognostic indicator of survival and recurrence in tethered or fixed rectal carcinoma after preoperative chemotherapy and radiotherapy. Int $\mathrm{J}$ Radiat Oncol Biol Phys. 2005; 61:665-677. 